\title{
Legitimacy of hysterectomy to solve the "problem" of menstrual hygiene in adolescents with intellectual disability
}

\author{
Horacio Márquez-González ${ }^{1}$ and Edith Valdez-Martínez² \\ ${ }^{1}$ Instituto Mexicano del Seguro Social, Centro Médico Nacional Siglo XXI, Cardiology Hospital; ${ }^{2}$ Instituto Mexicano del Seguro Social, Health
} Research Coordination, Ciudad de México, Mexico

\begin{abstract}
Menstrual hygiene in adolescents with intellectual disability (ID) represents an extra burden for parents or primary caregivers, especially in developing countries, where social institutions, including the health system, lack the capability to help this group of teenagers and their families; hence, hysterectomy to eliminate menstrual bleeding is considered a morally acceptable resource. Hysterectomy to solve the "problem" of menstrual hygiene reflects obstacles that affect the care provided by the physician to the adolescent with ID: on one hand, the criterion of social value about a "poor quality of life," and on the other, discrimination when only socioeconomic conditions are considered rather than the lack of a social network of support and special education. In Mexico, current medical support for girls and adolescents with ID for the management of menstrual hygiene is unsatisfactory. The practice of hysterectomy with the single purpose of menstrual hygiene is ethically and morally unfair and maleficent.
\end{abstract}

KEY WORDS: Sterilization. Adolescents. Medical ethics. Menstruation. People with disabilities.

\section{Introduction}

\section{Epidemiology of intellectual disability (ID)}

The United Nations Organization, through the Statistical Conference of the Americas Executive Committee of the Economic Commission for Latin America and the Caribbean, reported a total population of $557,148,402$ inhabitants in Latin America in 2014, out of which $12.6 \%(70,233,000)$ had some type of disability. ${ }^{1}$ The document The State of World's Children 2013: Children with Disabilities, published by the United Nations Organization in 2013, indicated a worldwide frequency of 13 million children with some type of disability and estimated that one out of every 20 children suffers from it in moderate to severe degree.

In Mexico, the latest official data come from the National Institute of Statistics and Geography, which in the document Disability in Mexico, figures by 2014 indicates that until that year there were 120 million people living in the country, with an estimated prevalence of disability of $6 \%\left(47.3 \%\right.$ adults). ${ }^{2}$ With regard to females between 0 and 14 years of age, the main causes of disability were problems at birth (44\%) and illness (26.9\%); $42.8 \%$ were classified with limitations to learn, recall or concentrate, $25.7 \%$ with difficulty to bathe, get dressed or eat and $16.6 \%$ with disability to verbally communicate. As for fertility, a history of pregnancy was documented in $9 \%$ of females between 15 and 19 years of age, in $44 \%$ between 20 and 24 years and in $69.6 \%$ between 25 and 29 years, with an overall average of children of 2.1 .

As regards health services, $35 \%$ of females were found to be affiliated to a hospital of the Ministry of Health and $32.7 \%$ to the Mexican Institute of Social Security; $13.3 \%$ were classified as illiterate.

In 2012, the National Institute of Statistics and Geography also published The national directory of associations of and for people with disabilities, where
Correspondence: Horacio Márquez-González

E-mail: horacioinvestigacion @ hotmail.com
Date of reception: 29-05-2018

Date of acceptance: 18-07-2018

DOI: 10.24875/GMM.M19000206
Gac Med Mex. 2018;154:550-557

Contents available at PubMed www.gacetamedicademexico.com 
988 societies were registered, out of which 830 (84 \%) serve pediatric population and 557 (56\%) serve people with ID in particular. The activities carried out by the societies that assist people with ID are of recreational and cultural nature (108, $37 \%)$, training for venturing into working tasks (144, $26 \%)$, psychological counseling (167, $30 \%)$, special education (147, $26 \%)$, physical rehabilitation (164, $29 \%)$, medical care $(82,15 \%)$ and hospitalization services (less than $2 \%$ ). None of the societies has a gynecologist or a pediatrician. $^{3}$

To consider the ID diagnosis, the World Health Organization International Disease

Classification ${ }^{4}$ indicates that intellectual level must be below average to acquire basic skills for functioning, survival (communication, self-care, life at home, social skills, use of the community, self-direction, health and safety, academic functional skills, leisure and work) and of onset prior to 18 years of age. It classifies ID according to the degree of intellectual coefficient as mild (50 to 69 points), moderate (35 to 49 points), severe (20 to 34 points) and profound ( $<19)$ points). ${ }^{5}$

People with ID can face concomitant health problems, which in adolescents include those related to puberal development and menstruation effects. Coexistence of health problems such as contractures, relative immobility or behavioral difficulties might limit the participation of the adolescent in her personal hygiene. Thus, the dependency for menstrual/personal hygiene becomes a problem both for parents or caregivers and for adolescents with DI themselves. For the former, said dependence for hygiene represents an additional burden (social, psychological and economic), ${ }^{6}$ and for the latter, it may represent an increase in the likelihood of aggression or sexual abuse by caregivers. ${ }^{7}$

Among the different diagnostic-therapeutic interventions to address the menstrual bleeding problem, the following can be mentioned:

- Educational maneuvers: ${ }^{8}$ Richman et al. employed educational routines in four women with mild and moderate DI. The results of the educational routines employed were directly and positively related to continuous reinforcement thereof. ${ }^{9}$ Watson demonstrated that training plans can be developed with favorable results for the reinforcement of self-care behaviors if physical characteristics, attitudes and perceptions of adolescents with ID are previously considered, together with possible support network and health system characteristics. ${ }^{10}$ However, when interrogating mothers of adolescents with profound ID, Chou found that educational routines are perceived as insufficient and that for families they represent an disruption of activities and increase family expenses. ${ }^{11}$

- Hormone therapy: this option comprises a wide range of possibilities, from oral contraceptives to the use of intrauterine devices. Immediate results are satisfactory to inhibit or decrease menstrual bleeding. It is the first-line treatment of choice in cases with no medical contraindications, such as recent thrombotic events or that the adolescent with ID suffers any type of epilepsy that can exacerbate with hormone therapy. ${ }^{12}$

- Endometrial ablation: one meta-analysis showed that endometrial ablation can be as effective as hormone therapy; however, the results reveal that it causes pain during the post-surgery months. ${ }^{8}$ There are no published reports with long-term follow-up of results.

- Hysterectomy: the series of published cases of women with ID and hysterectomy indicate minimally frequent or no perioperative and postsurgical complications, in addition to high satisfaction of parents or caregivers; however, there are no published reports with medium and long term follow-up. ${ }^{13,14}$

International guidelines and legal documents in force in Mexico (Table 1) that allude to hysterectomy and menstrual hygiene highlight three ethical aspects: respect for the autonomy of adolescent girls with ID, the best interest criterion focused on the adolescent and, hand in hand with these two, the rights of the adolescent in question. ${ }^{15-22}$

In the Mexican context, the State is not actively involved in issues related to the health and well-being of adolescents with ID: there are no specific educational programs, there is no financial or other kind of support for the families of this group of adolescents and, as a consequence, the families (usually the mothers) are the sole responsible and who face the important demand generated by an adolescent girl with ID in a situation of full dependence.

In view of these circumstances, and given the scientific-technological advances and low surgical morbidity of hysterectomy, it is logical that complete and permanent suppression menstrual bleeding is preferred. In addition, non-therapeutic hysterectomy for menstrual hygiene purposes in adolescents with ID is a non-regulated procedure in Mexican hospitals, and 
Gaceta Médica de México. 2018;154

Table 1. Related international and national documents on hysterectomy and menstrual hygiene in females with intellectual disability

Organization or Decree (D), law (L) or regulation (R) Statute

country

Universal declaration of human rights

UN

Convention on the rights of the child

$122^{\text {nd }}$ consulting council meeting. Female genital mutilation, Secretariat report

Sexuality and human rights

Convention on the rights of people with disability

UNESCO Puberty and education on menstrual hygiene

CEDAW General recommendation about females and health

FIGO Committee for the Ethical Aspects of Human Reproduction and Women's Health

United States American college of obstetricians and Gynecologists

General statute for the inclusion of people with disability

Federal law to prevent and eliminate discrimination

General statute on the rights of girls, boys and teenagers
Article 2: "Everyone is entitled to all the rights and freedoms set forth in this Declaration, without distinction of any kind..."

Article 3: "Everyone has the right to life, liberty and security of person".

Article 16: "Men and women of full age, without any limitation..., have the right to marry and to found a family".

Article 2 (D): "... that all human beings under the age of 18 years shall not be discriminated against, including the issue of mental health."

Article 24.3 (Pact). "Avoid all kinds of sex organ mutilation for any reason."

Paragraph 2: "... to protect girls and women from all forms of violence, in particular female genital mutilation ..."

Article 4 (L). "Respect for bodily integrity."

Article $9(\mathrm{~L})$. "Freedom to decide to have or not to have, and when to have children".

Article $23(\mathrm{~N})$. "Recognize the right of the person with disability, access to sex education and reproduction methods".

Recommendation. "7-lesson-validated program for education on menstrual hygiene that can be taught by teachers and tutors".

Articles 10, 12, 15 and 16 (R)

"Forced sterilization is a violation of human dignity."

Contraception chapter, recommendation $6(\mathrm{~N})$ :

"...performing definitive sterilization procedures is an inappropriate behavior by treating physicians."

Recommendation 5: "... if the woman has severe ID .... or if she does not have the ability to maintain adequate personal hygiene during menstruation, it is ethically and medically prudent to search a medical or surgical option, the least invasive possible."

Article $7(\mathrm{~L})$ : "... Right of people with disability to enjoy the highest level of health, rehabilitation and habilitation without discrimination."

Article $7(\mathrm{~L})$ : "... Right of people with disability to enjoy the highest level of health, rehabilitation and habilitation without discrimination."

Article 7X (L). "To create orientation, education and sexual and reproductive rehabilitation programs for people with any disability."

Article 11.II (L). "To impart education to preserve health, knowledge of sexuality, family planning, responsible parenthood and respect for human rights."

Article 50 (V). "To develop preventive health care, guide those exercising parental authority or guardianship in matters of sexual and reproductive health."

Article 50 (XIII). "To prohibit, sanction and eradicate forced sterilization of girls, boys and adolescents and any obstetric violence."

UN = United Nations, UNESCO = United Nations Educational, Scientific and Cultural Organization; CEDAW = Convention on the Elimination of All Forms of Discrimination against Women, FIGO = International Federation of Gynecology and Obstetrics. 
the decision to perform it is not always submitted to a hospital bioethics committee. In this regard, important ethical questions arise on how to balance the health interests of adolescent girls with ID with the needs, desires and interests of parents/primary caregivers and societal interests and if non-therapeutic hysterectomy is justified for menstrual hygiene purposes in adolescents with ID in countries like Mexico.

The purpose of this manuscript is to favor reflection on an archetypal ethical problem (non-therapeutic hysterectomy in adolescents with ID) that pediatric clinicians face in their clinical practice. Above, the objective characteristics of three real cases are presented (analyzed by the hospital bioethics committee of a pediatric hospital of Mexico City).

\section{Discussion}

\section{Case 1}

This is the case of a 12-year-old adolescent female who lives in the bosom of a uniparental family, with her 34-year-old mother. She has no perinatal history relevant to the case.

Personal pathological history: at 17 days of birth she presented with bronchoaspiration with asystole, which required ventilatory mechanical support for 2 months, during which he suffered from necrotizing enterocolitis and seizures; since then, the diagnoses of infantile cerebral palsy and convulsive syndrome secondary to hypoxic-ischemic encephalopathy were added. At seven years of age, she was diagnosed with insulin-dependent diabetes mellitus.

Neurological and psychiatric evolution: since 10 years of age, she was controlled with anticonvulsant monotherapy. The child and adolescent psychiatry department diagnosed anxiety and impulsivity behavior, on treatment with fluoxetine and risperidone. She was classified with severe ID, and thus she attends a special school.

Gynecological evaluation: menarche since 11 years, with irregular cycles of between five and eight days' duration and with normal volume. Uterine and urinary tract abnormalities were ruled out by ultrasound and pelvic tomography.

Problem: the mother is the primary caregiver and sole economic provider. The school and the child and adolescent psychiatry department indicated uninhibited behaviors, and thus they recommended the mother that the adolescent should have hysterectomy performed, which was accepted by the mother and the procedure was carried out at the pediatric surgery department.

Behavioral problems in adolescents with DI such as the aforementioned (uninhibited behaviors and non-adherence to social rules of behavior) not only illustrate the issue of adolescent self-care, but the social symbols attributed to menstruation: uninhibited behaviors, understood in hormonal terms, the possibility of reproducing (which by not being an option leads to think that the uterus is unnecessary, just like the teaching of menstrual hygiene) and the traumatic nature of a pregnancy under these circumstances for all those involved..$^{12,23}$ By eliminating those problems, hysterectomy would increase the "quality of life" of the adolescent with ID. However, there is evidence objecting this.

The arguments for performing hysterectomy should be based on the fact that the benefits obtained by permanently suppressing menstruation would be greater than the harm inflicted. International ethics guidelines and Mexican legal documents (Table 1) grant a great value to the right to reproduction and to bodily integrity of adolescents with ID; in this context, eliminating their physical capacity for reproduction would be regarded as a mutilation.

In a meta-analysis on menstrual health that included primary studies in developing countries, Chandra-Mouli showed the vagueness of the measurements used to describe adolescents' menstrual experiences. ${ }^{24}$ In turn, the World Health Organization indicates that $93 \%$ of girls with ID are victims of sexual abuse and that in up to $54 \%$ of cases, the abuse is perpetrated in their homes. ${ }^{25}$ This indicates that, regardless of the behavior of the adolescents in question, the physical and intellectual dependence they are subjected to exposes them to sexual abuse, and thus hysterectomy does not exempt them from being attacked; on the contrary, it can overexpose them once the possibility of pregnancy is cancelled. The premises that make up this counterargument also apply to case 2 .

\section{Case 2}

This is the case of a 12-year-old adolescent female who lives in the bosom of a nuclear family, with mother and father of 30 and 34 years of age, respectively. There was no significant perinatal history relevant to the case. 
Personal pathological history: at her school-age stage she developed a reddish protrusion of $1 \mathrm{~cm}$ in diameter in the occipital region and seizures; the diagnosis was occipital dermal sinus and epilepsy.

Neurological and psychiatric evolution: the adolescent had her seizures controlled. Her ID was categorized as moderate, in need of support by caregivers for personal hygiene.

Gynecological evaluation: precocious puberty was diagnosed, even without menarche. Uterine and annex structures ultrasound showed no structural alterations.

Problem: the parents asked the treating doctors to carry out hysterectomy, arguing that when the time came, the girl would require support for personal hygiene during menstrual bleeding. The request was accepted by the department of pediatric surgery and hysterectomy was performed prior to menarche.

The power that parents have over their children derives, on one hand, from the duty they have to care for, to raise and govern the actions of their children under $\mathrm{age}^{25}$ and, on the other, from the fact that the decisions made will affect not only the life and well-being of their child (the adolescent girl in this case), but also carry emotional, economic and other consequences for themselves. The adolescent is incapacitated for autonomous decision-making, both because of her age and her ID, hence parental authority in decision making is naturally accepted. In international ethical guidelines and national documents (Table 1), the criterion of the best interest of the adolescent with ID must be the rule for others (parents, caregivers, doctors) to make decisions instead of her. The risk-benefit evaluation should be exclusively focused on the adolescent with ID, which excludes the interests of decision makers, be it the parents, doctors or society.

However, the argument made against not considering decision makers' interests should also be taken into account, since their exclusion (in the Mexican context) might affect the well-being of the adolescent with ID. Case 2 teenager has both father and mother, and hysterectomy might benefit (because it would eliminate stress and fear of the parents deriving from possible pregnancies and the burden that menstrual hygiene entails) or harm her (because it would be violating her individual rights). This ethical questioning applies equally in case 1 , where the mother is the primary caregiver and the only family support; similarly, permanent suppression of menstrual bleeding of the adolescent with ID might benefit her (because it would allow the mother to continue with economic contribution) or harm her (for the same expounded reason).

When the interests of "others" predominate in decision-making, potential benefits can be misleading and distort the doctor-patient relationship. Medical care based on the fiduciary concept forces treating physicians to perform a comparative analysis (of benefits and risks or inherent costs, corresponding to the different management alternatives) that allows them to identify the maximum net benefit for the adolescent. ${ }^{26}$ Surgically removing the uterus of adolescent girls for menstrual hygiene purposes means exposing them to an elevated risk of suffering unavoidable and concomitant diseases to this type of surgical intervention; then, it is impossible not wondering if defecation (which is also physiological and with bad hygiene increases the risk of infections) warrants similar radical decisions. ${ }^{27}$

\section{Case 3}

This case is about a 13-year-old adolescent girl about whom structural characteristics of her family are unknown. She has no perinatal history relevant to the case.

Personal pathological history: accidental ingestion of glibenclamide at three years of age, which caused hypoglycemic encephalopathy and asystole that required resuscitation with chest compression, assisted mechanical ventilation and tracheotomy; she presented with difficult-to-control seizures that caused extensive cerebral infarctions.

Neurological and psychiatric evolution: seizures that are difficult to control with more than three anticonvulsants. She has severe ID and spastic quadriparesis.

Gynecological evaluation: menarche since 13 years of age with dysfunctional uterine bleeding with hypermenorrhea (anemia and poor general hygiene have been documented). Pediatric gynecology clinical data contraindicated the use of estrogen due to a history of cerebral infarctions; in addition, seizure control loss was reported with progestogen initial use.

Problem: she has severe ID that determines total dependence. She has experienced hypermenorrhea with organic repercussion. First-line hormone treatments may increase the risk of cerebral infarction and seizure control loss. Due to all the above, the pediatric surgery department recommended hysterectomy. In 


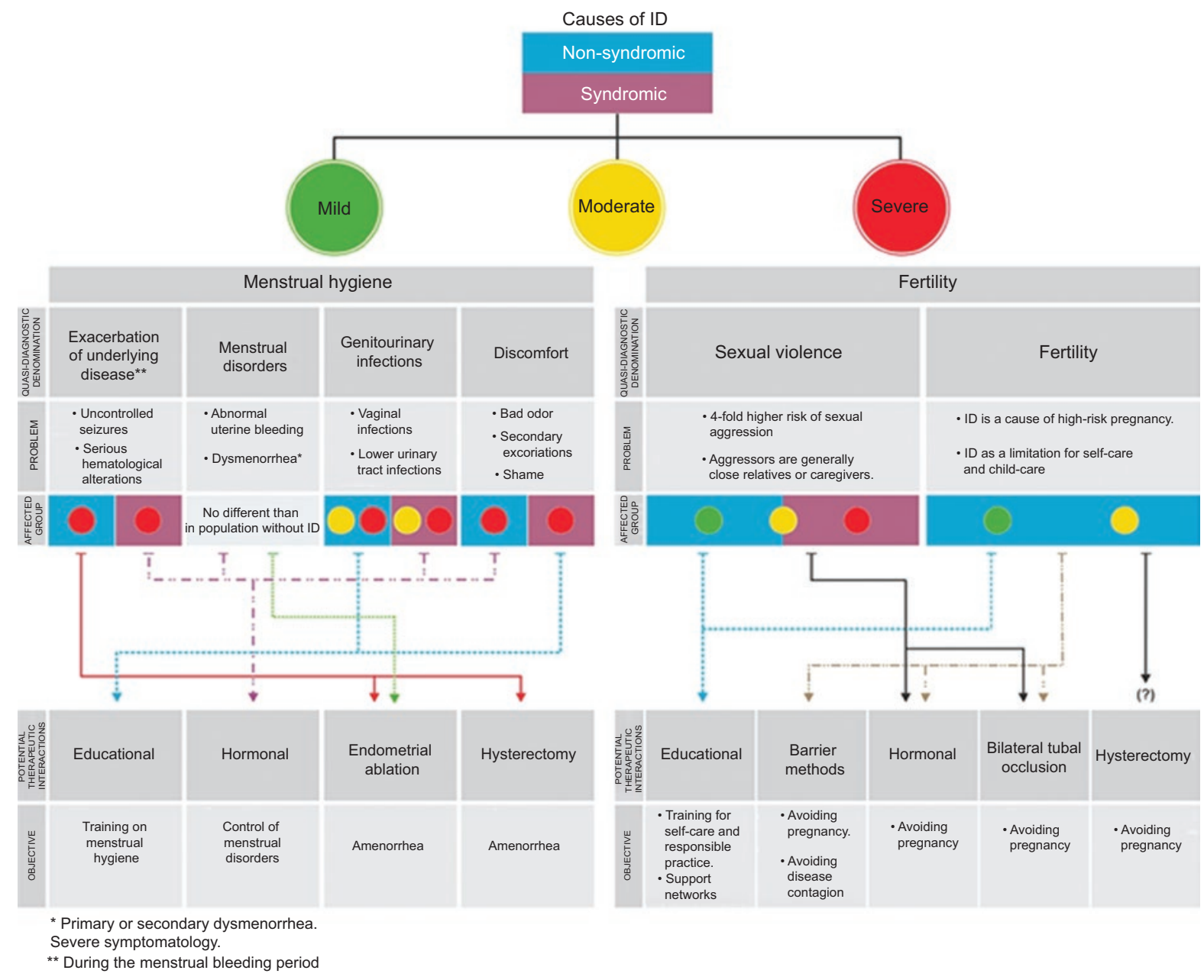

Figure 1. Some factors that should influence on decision making for the management of menstrual hygiene and fertility in female adolescents with intellectual disability (ID). In this image, the argument for hysterectomy performance in adolescents with ID with menstrual hygiene and fertility purposes is schematized. It should be read downwards; the purple and blue colors (in rectangle) represent the ID etiology, while the green, yellow and red colors (in circles) schematize the degree of ID. The arrows are directed towards the arguments and objectives of therapeutic possibilities.

this case, endometrial ablation could have been another alternative. ${ }^{28}$

According to Beauchamp and Childress, ${ }^{29}$ decision making in the doctor-patient relationship cannot, by definition, be always and solely based on biological criteria or any other type of personal medical values, because it would be, in many situations (as in this case), supported by a partial view of the facts. Should we think that the hysterectomy performed on this adolescent is a case of discrimination? Discrimination consists in treating adolescents with ID in a different way than others when there are no relevant differences justifying it. While it is true that the literature reports a very low frequency of surgical complications with hysterectomy and high parental satisfaction, ${ }^{30,31}$ there are no published reports with medium and long-term follow-up. Justice requires, at least, supervision of clinical practice protocols in order to determine if there are discriminatory effects.

\section{Global analysis}

An ethical analysis of the three presented cases generates additional questionings that deserve discussion.

If the content of the obligation of the doctor to be beneficial is exclusively determined by the parents or primary caregivers needs, wishes and interests, "respect for autonomy" has triumphed rather than beneficence. Then, this is objectionable, because the exercise of autonomy is not only a status that should be granted (to the parents), but a process wherein the doctor actively participates to help creating it. In all three cases, the parents accepted the hysterectomy 
proposed by the doctors and, therefore, their ability to understand and decide had not to be assessed. If to the above the fact is added that the potential results of hysterectomy are usually presented to the parents in terms of "better quality of life" (given the almost null probabilities of surgical complications, elimination of menstrual bleeding and, therefore, of unwanted pregnancies), acceptance of hysterectomy by the parents is expected. Then, it would be naive thinking that there was really respect for autonomy, since the best interest criterion was intimately linked to the parents/ caregivers preferences.

In this same line of reasoning, international ethics guidelines and national legal documents point out the importance of the adolescent with ID's consent; in this regard, Beauchamp and Childress ${ }^{29}$ indicate that risk assessment of the different alternatives can be easily influenced by the way risks and gains are presented. Therefore, adolescent girls with ID, even those with mild ID, could be immature (in view of the complexity of the decision) and easily manipulated.

The predominance of physicians' biological approach, restricted to the care of organic diseases, leaves aside the fact that adolescents with ID are biopsychosocial units, i.e., persons entitled to physical integrity. Beneficence offers the primary goal and the fundamental reason of medicine, but authentic justice, no maleficence and respect for autonomy fix the moral limits to professional actions in the search for that goal.

In countries like Mexico, where hospital bioethics committees (HBCs) are of recent creation, the simple obligation for non-therapeutic hysterectomy in girls and adolescents with ID to be determined by the HBC is not sufficient per se, but prior it is required for HBCs development to be really promoted by improving their operating procedures and policies. ${ }^{32}$

ID creates profound and significant disadvantages in the female adolescent who suffers from it, reducing her capacity to live properly. Justice is carried out if health care resources are used to counteract those disadvantages, returning adolescents with ID an opportunity to use their abilities. Finally, and continuing with this line of reasoning, the factors that should influence on decision making for the management of menstrual hygiene and fertility in the group of adolescents with ID are presented in Figure 1.

\section{Conclusion}

Current medical assistance to girls and adolescents with $\mathrm{DI}$ for the management of menstrual hygiene is far from being satisfactory. It is not the intention whereby non-therapeutic hysterectomy is practiced on girls and adolescents with ID (e.g., for menstrual hygiene, to avoid unwanted pregnancies, to reduce the burden on parents/caregivers) but the reason that drives its performance in this group of girls and adolescents (the fact of considering them with a lower moral status than that of persons, basing the decision of the procedure on the value these adolescents have for others), what entails heavier weight and moral relevance.

\section{References}

1. Informe de la Decimotercera Reunión del Comité Ejecutivo de Conferencia Estadística de las Américas de la Comisión Económica para América Latina y el Caribe. Chile: Organización de las Naciones Unidas/ Conferencia Estadística de las Américas de la Comisión Económica para América Latina y el Caribe; 2014.

2. Instituto Nacional de Estadística y Geografía. Las personas con discapacidad en México: una visión al 2010. México: Instituto Nacional de Estadística y Geografía; 2013

3. Instituto Nacional de Estadística y Geografía. Directorio Nacional de Asociaciones de y para personas con Discapacidad. México: Instituto Nacional de Estadística y Geografía; 2012.

4. Clasificación Internacional del Funcionamiento, de la Discapacidad y de la Salud (CIF). Chile: Departamento de Estadística e Información de Salud; 2001.

5. The International Classication of Functioning. Disability and Health (ICF). Suiza: World Health Organization: 2016.

6. Emerson E. Mothers of children and adolescents with intellectual disability: social and economic situation, mental health status, and the self-assessed social and psychological impact of the child's difficulties. J Intellect Disabil Res. 2003;47:385-399.

7. Koff E, Rierdan J. Preparing girls for menstruation: recommendations from adolescent girls. Adolescence. 1995;30:795-811.

8. Bhattacharya S, Middleton LJ, Tsourapas A, Lee AJ, Champaneria R, Daniels JP, et al. Hysterectomy, endometrial ablation and Mirena $₫$ for heavy menstrual bleeding: a systematic review of clinical effectiveness and cost-effectiveness analysis. Health Technol Assess. 2011;15:1-252.

9. Richman GS, Ponticas Y, Page TJ, Epps S. Simulation procedures for teaching independent menstrual care to mentally retarded persons. Appl Res Ment Retard. 1986;7:21-35.

10. Watson J. Assumptions of decision-making capacity: the role supporter attitudes play in the realisation of article 12 for people with severe or profound intellectual disability. Laws. 2016;5:1-9.

11. Chou YC, Lu ZY. Caring for a daughter with intellectual disabilities in managing menstruation: a mother's perspective. J Intellect Dev Disabil. 2012;37;1-10.

12. Kassebaum N, Kyu HH, Zoeckler L, Olsen HE, Thomas K, Pinho C, et al. Child and adolescent health from 1990 to 2015: Findings from the Global Burden of Diseases, Injuries, and Risk Factors 2015 Study. JAMA Pediatr. 2017:171:573-592.

13. Grosspietzsch R, Von-Mittelstaedt G. Work disability following gynecological operations. Gynakologe. 1991;24:235-237.

14. Sheth S, Malpani A. Vaginal hysterectomy for the management of menstruation in mentally retarded women. Int J Gynaecol Obstet. 1991;35: 319-321.

15. Organización Mundial de la Salud. Mutilación genital femenina: informe de la Secretaría. Mutilación genital femenina. Informe de la Secretaría. Ginebra, Suiza: Organización Mundial de la Salud; 2008.

16. Centro Internacional de Derechos Humanos y Desarrollo Democrático. Sexualidad y derechos humanos. Canadá: 2010.

17. United Nations Educational, Scientific and Cultural Organization. Good policy and practice in health education. Booklet 9 . Puberty education and menstrual hygiene management. Francia: UNESCO; 2014

18. DerechosHumanos.net. [Sitio web]. Comité para la eliminación de la discriminación contra la mujer (CEDAW) de Naciones Unidas DH. Disponibel en: https://www.derechoshumanos.net/ONU/ComiteEliminacionDiscriminacionContraMujer-CEDAW.htm.

19. Obstetrics FloGa. Ethical issues in obstetrics and gynecology by the FIGO Committee for the Study of Ethical Aspects of Human Reproduction and Women's Health. Londres: FIGO; 2012.

20. Ley general para la inclusión de personas con discapacidad. México: Diario Oficial de la Federación; 2011. 
21. Ley federal para prevenir y eliminar la discriminación México: Diario Oficial de la Federación 2018 Jul 12.

22. Ley general de los derechos de niñas, niños y adolescentes. México: Diario Oficial de la Federación; 2014

23. Bonomi A, Nichols E, Kammes R, Green T. Sexual violence and intimate partner violence in college women with a mental health and/or behavior disability. J Womens Health (Larchmt). 2018;27:359-368.

24. Chandra-Mouli V, Patel SV. Mapping the knowledge and understanding of menarche, menstrual hygiene and menstrual health among adolescent girls in low- and middle-income countries. Reprod Health. 2017;14:30.

25. Comisión de Derechos de la Mujer e Igualdad de Género. Informe con recomendaciones destinadas a la Comisión sobre la lucha contra la violencia ejercida sobre las mujeres. Francia: Parlamento Europeo; 2014.

26. Tejedor-Torres JC, López-De-Heredia-Goya J, Herranz-Rubia N, Nicolás-Jimenez P, García-Munóz F, Pérez Rodríguez J, et al. Recommendations on making decisions and end of life care in neonatology. An Pediatr (Barc). 2013;78:190.
27. Guidelines on determinating the best interest of the child. Suiza: United Nations High Commissioner for Refugees; 2008.

28. Rodgers J, Lipscombe J. The nature and extent of help given to women with intellectual disabilities to manage menstruation. J Intellect Dev Disabil. 2005;30:45-52.

29. Beauchamp T, Childress J. Principles of biomedical ethics. EE. UU.: Oxford University Press; 1994.

30. Desai S, Campbell OM, Sinha T, Mahal A, Cousens S. Incidence and determinants of hysterectomy in a low-income setting in Gujarat, India. Health Policy Plan. 2017;32:68-78.

31. Passer A, Rauh J, Chamberlain A, McGrath M, Burket R. Issues in fertility control for mentally retarded female adolescents: II. Parental attitudes toward sterilization. Pediatrics. 1984;73:451-454.

32. Valdez-Martínez E, Mata-Valderrama G, Bedolla M, Fajardo-Dolci GE. Ethics committees in the experience of the IMSS: a Latin American instance. Rev Med Inst Mex Seguro Soc. 2015;53:490-503. 